Elsevier Editorial System(tm) for Journal of Petroleum Science and Engineering Manuscript Draft

Manuscript Number: PETROL2183R1

Title: A Laboratory Investigation of Water Abatement Chemicals for Potential Use in the Wanaea

Field

Article Type: Research Paper

Keywords: Chemicals treatment; Core flood; Laboratory studies

Corresponding Author: Mr Hiwa H Amin Sidiq, M.D.

Corresponding Author's Institution: Curtin University

First Author: Hiwa Sidiq, M.D.

Order of Authors: Hiwa Sidiq, M.D.; Robert Amin, Professor; Tony Kennaird , M.D.

Abstract: The disadvantages of water influx into a producing well include reduced relative permeability to hydrocarbon and increased expenses for both water handling and corrosion control. An effective water control technique is, therefore, highly desirable. One potential solution for reducing excessive water production is the injection of "Relative Permeability Modifier" (RPM) chemicals into producing wells. The work described in this paper is concerned with finding a highly selective chemical to reduce water production without affecting oil production. Presented herein are results of laboratory tests using relative permeability modifiers in conjunction with core samples from the Wanaea field.

The oil producing Wanaea field is operated by Woodside Energy. This field is in offshore Western Australian waters. Some of the wells suffer from high water cut, therefore the introduction of a relative permeability modifier (RPM) has been considered. 
Four RPM chemicals were tested with core plugs taken from Unit II of well Wanaea-3 (core depth 2832.00 to $2844.50 \mathrm{~m}$ ). Laboratory experiments were conducted on 4 reservoir core plugs, with air permeabilities ranging from 158 to $334 \mathrm{md}$ and porosities from 16.4 to $19.9 \%$. The objective of the tests was to assess the effectiveness of selected RPM's in selectively reducing water production.

The experimental results demonstrated that the chemicals were variably effective in reducing the relative permeability to the water phase, but they also variably affected the relative permeability to the oil phase. 


\begin{tabular}{|c|c|c|c|c|c|c|}
\hline No. & Where & Page & Paragraph & Line No. & Before & After \\
\hline 1 & Abstract & 1 & 1 & 4 & Relative permeability modifier & Relative Permeability Modifier \\
\hline 2 & Abstract & 1 & 2 & 1 and 2 & $\begin{array}{l}\text { Woodside Energy offshore } \\
\text { Western Australia. Some of the } \\
\text { wells }\end{array}$ & $\begin{array}{l}\text { Woodside Energy. This field is } \\
\text { in offshore Western Australian } \\
\text { waters. Some of wells }\end{array}$ \\
\hline 3 & Abstract & 1 & 4 & 1 & demonstrate & demonstrated \\
\hline 4 & Manuscript & 1 & 1 & 5,6 & 40 US\$, $\$ 5-10$ billion & \$US 40, \$US 5-10 billion \\
\hline 5 & Manuscript & 1 & 1 & 10 & Hence, Water & Hence, water \\
\hline 6 & Manuscript & 1 & 2 & 2 & to rock surface & to the rock surface \\
\hline 7 & Manuscript & 1 & 4 & 2 & $\begin{array}{l}\text { chemical formulated at Curtin } \\
\text { University by Professor Amin } \\
\text { (RAC) }\end{array}$ & $\begin{array}{l}\text { Chemical (RAC) formulated at } \\
\text { Curtin University by Professor } \\
\text { Amin }\end{array}$ \\
\hline 8 & Manuscript & 1 & 5 & $2,3,4$ & $\left(110^{\circ} \mathrm{C}\right),(2250 \mathrm{psi}), 24000 \mathrm{mg} / \mathrm{l}$ & $\left(110^{\circ} \mathrm{C}\right),(2250 \mathrm{psi}), 24000 \mathrm{mg} / \mathrm{l}$ \\
\hline 9 & Manuscript & 2 & 1 & 4,7 & $7.3 \mathrm{~cm}$ in length and $3.80 \mathrm{~cm}, \ldots$ & $7.3 \mathrm{~cm}$ in length and $3.80 \mathrm{~cm}$, \\
\hline 10 & Manuscript & 2 & 3 & 1 & ,RAC) & , RAC) \\
\hline 11 & Manuscript & 3 & 2 & 3,4 & $\begin{array}{l}(\mathrm{Kw} 1=25.9 \mathrm{md}, \mathrm{Kw} 2=7.1 \mathrm{md}), \\
\text { Kw2@WeterWeb }\end{array}$ & $\begin{array}{l}(\mathrm{Kw} 1=25.9 \mathrm{md}, \mathrm{Kw} 2=7.1 \\
\mathrm{md}), \mathrm{Kw} 2 @ \text { WeterWeb }\end{array}$ \\
\hline 12 & Manuscript & 3 & 3 & 3 & $\mathrm{~F}_{\text {rro }}$ & $\left(\mathrm{F}_{\text {rro }}\right)$ \\
\hline 13 & Manuscript & 4 & 5 & $3,4,8,9,12$ & $\begin{array}{l}\left(\mathrm{F}_{\text {rrw2 } 2),\left(\mathrm{F}_{\text {rrw1 }}\right) \text {, oil(Liang, }}\right. \\
(1989)^{10}, \mathrm{~F}_{\text {rrw }} \text { lie }\end{array}$ & $\begin{array}{l}F_{\text {rrw2 }}, F_{\text {rrw1 }} \text {, oil (Liang, (1989), } \\
F_{\text {rrw }} \text { that lie }\end{array}$ \\
\hline 14 & Manuscript & 5 & 1 & 3,5 & $\begin{array}{l}\text { are shown in the table5, } \\
\text { (Kw@Sor). }\end{array}$ & $\begin{array}{l}\text { is shown in the Figure 3, }(\mathrm{Kw} @ \text {, } \\
\text { Sor). }\end{array}$ \\
\hline 15 & Manuscript & 5 & 4 & 1 & $\begin{array}{l}\text { Authors like to thank Woodside } \\
\text { Energy to }\end{array}$ & $\begin{array}{l}\text { Authors wish to thank Woodside } \\
\text { Energy for }\end{array}$ \\
\hline 16 & Table & 1 & & 4 & RA & RAC \\
\hline
\end{tabular}




\section{${ }^{*}$ Revision, changes marked}

\section{Introduction}

Excessive water production is an inevitable consequence of declining oil production when waterflooding is used to develop an oil reservoir or when the field drive mechanism involves strong aquifer support. It is a problem of paramount importance from technical, environmental and oil production points of view (Amanullah, 2006). The remedy of excessive water production costs worldwide \$US 40 billion annually, whereas in the U.S the disposing cost of this water is estimated to be \$US 5-10 billion (Bailey et al., 2000). These costs include the expense to lift, dispose or re-inject, and the capital cost of surface facility construction to ensure that environmental regulations are met (Halliburton, 1996). Hence, water control should not be seen only in terms of increasing incremental oil production, but also in terms of reduction of operating costs associated with water production, both material and environmental (Kume, 2003). Therefore a technology that can block water in situ is highly desirable.

Downhole treatment based on polymers called relative permeability modifiers (RPM), works on the basis of the chemicals attaching themselves to the rock surface to reduce water mobility. This technique for conformance control has been often represented as a valid and economic alternative solution. However each RPM technology needs detailed pre-application testing to ensure the treatment will be appropriate in terms of it is applicability to the particular reservoir mineralogy, permeability, brine salinity, temperature and pressure (Zaitoun et al., 1989; Seright, 1993; Mennella, 1998).

The objective of this study is to evaluate chemicals that might effectively reduce water production in the Wanaea reservoir, situated offshore on the Australian North West Shelf. As some of the wells are producing high water cut, chemical abatement has been proposed, with the aim of reducing water production selectively without any significant reduction in hydrocarbon production. Core tests have been undertaken to examine the effectiveness of four different chemicals at reservoir conditions.

Three commercially available chemicals (WaterWeb, Reltreat and AquaCon) plus a research chemical (RAC) formulated at Curtin University by Professor Amin were tested. Reservoir parameters such as formation brine salinity, temperature, reservoir rock mineralogy and oil properties were taken into consideration for detailed formulation of the chemicals.

\section{Test Methods}

Linear core flooding experiments were performed on the Wanaea core samples with the aim of evaluating various RPM chemicals at reservoir conditions of temperature $\left(110{ }^{\circ} \mathrm{C}\right)$ and effective overburden pressure ( $2250 \mathrm{psi}$ ). The simulated brine used in the tests was prepared by dissolving 24 grams of $\mathrm{NaCl}$ in each litre of solution using distilled water. The resulting $24000 \mathrm{mg} / \mathrm{l}$ salinity approximated the salinity of the Wanaea formation brine. The oil used in this study was filtered stock tank Wanaea crude. 


\section{Core Plug Preparation and Testing}

The core plugs used in the tests were from the Wanaea reservoir. Basic core analysis measurements carried out by Core Laboratories Australia indicated that the air permeability ranged from 158 to $334 \mathrm{mD}$ and the porosity varied from 16.4 to $19.9 \mathrm{vol} \%$. The core plugs were approximately $7.3 \mathrm{~cm}$ in length and $3.80 \mathrm{~cm}$ in diameter. The properties and depths of the tested cores are listed in Table 1. The selected core plugs had been cleaned with toluene and methanol using soxhlet extraction before basic measurements of porosity and air permeability were performed.

The cores were evacuated and pressure saturated with the simulated formation brine and loaded individually into core holders for testing on a sequential basis. Each loaded sample was then placed in an air-bath and the temperature increased to the Wanaea reservoir representative temperature of $110{ }^{\circ} \mathrm{C}$. A confining pressure of $3250 \mathrm{psi}$ and a pore pressure of $1000 \mathrm{psi}$ were maintained throughout the analytical sequences. The core flood tests followed the sequence of steps as shown in Table 2, with some variation with respect to chemical injection as some of the chemicals required a pre-flush before the main chemical treatment.

Each of four samples was tested with a different RPM (Waterweb, Aquacon, Reltreat, RAC) while a fifth sample was used as a control. This control sample was subjected to the same sequence of testing (comprising multiple cycles of oil and water flow) as the other four samples except that there was no chemical treatment. Results from the control sample were used to determine whether or not variations in oil and/or water permeability were simply a result of hysteresis effects created by changes in fluids saturation distribution in the pore spaces during the multiple flow cycles.

The oil permeability at immobile water saturation (Ko@ Swi) and the water permeability at residual oil saturation (Kw@ Sor) were measured before chemical injection. After chemical injection all samples (except the control) were injected with one of the four chemicals under test and the following measurements were made:

--Kw1@ Sor: This permeability was compared directly to the value of Kw@ Sor before chemical injection to determine if any reduction in water permeability had taken place

--Ko1@ Swi: This permeability was compared to the value of Ko @ Sor measured before chemical injection to determine if chemical treatment had caused an unwanted reduction in oil permeability.

--Kw2@ Sor: This permeability was compared to both Kw @ Sor and Kw1@ Sor to determine if any water permeability reduction resulting from chemical injection (as demonstrated by Kw1 @ Sorvs Kw@ Sor) could be sustained after subsequent oil and water flush cycles (since substantial oil and water flushing of a chemically injected zone would occur around a treated production well in the reservoir). 


\section{Results and discussion:}

\subsection{Results:}

A point to be noted in the course of $100 \mathrm{PV}$ of brine flooding; water permeability at Kw1 and Kw2 were nearly stable after flooding the sample with approximately 15 pore volumes (PV) of water, except Reltreat chemical at Kw1 test ( See Fig $1 \&$ 2). Both RAC and Reltreat chemicals gain strength with time as water permeability (Kw1) decreases through the cycle of $100 \mathrm{PV}$ flooding. In contrast, WaterWeb and AquaCon chemicals show degradation with brine flooding (Kw1) up to $15 \mathrm{PV}$. This observation reflects the fact some of the chemical have broke down when the core is flushed with brine.

In general after subsequent flushing the sample with crude oil, water permeability has reduced remarkably at Kw2 if comparing Kw1 with $\mathrm{Kw} 2$ (See Fig 1 \& 2). The RAC sample is significantly affected by alternating oil and brine injection $(\mathrm{Kw} 1=25.9 \mathrm{md}, \mathrm{Kw} 2=7.1 \mathrm{md})$. However Kw1 \& Kw2@WeterWeb shows some variation but most of the flooding course stayed approximately at the same level (See Table 3). During the RAC chemical's injection a considerable amount of residual crude oil was mobilized, consequently water permeability (Kw1) is obviously increased because of the lower Sor. It is difficult to know the exact volume of oil mobilized as the chemical appears to be miscible with the oil.

\subsection{Residual Resistance Factor}

To facilitate comparison of results both for individual sample cycles and for the four different chemical treatments, the data is also expressed in terms of Residual Resistance Factors $\left(\mathrm{F}_{\mathrm{rr}}\right)$. High values of residual resistance factors $\left(\mathrm{F}_{\text {rrw }}\right)$ for brine flow and low $\left(\mathrm{F}_{\text {rro }}\right)$ values for gas/oil flow means that the chemicals have the ability to control water production with minor effects on gas production. The $\mathrm{F}_{\mathrm{rr}}$ to brine and gas were determined using equation:

$$
\mathrm{F}_{r r w}=K w_{\text {before }} / K w_{\text {affer }}
$$

Where

$K w_{\text {before }}=$ Water permeability before chemical treatments $(\mathrm{Kw} @$ Sor $)$.

$K w_{\text {affer }}=$ Water permeability after chemical treatments $(\mathrm{Kw} 1 \& 2)$.

For this research work residual resistance factor $\left(\mathrm{F}_{\mathrm{rr}}\right)$ to both brine and oil are calculated as follows for the subsequent cycles:

$\mathrm{F}_{\mathrm{rrw1}}=\mathrm{Kw} @$ Sor / Kw1@Sor

$\mathrm{F}_{\mathrm{rrw} 2}=\mathrm{Kw} @$ Sor $/ \mathrm{Kw} 2 @$ Sor

$\mathrm{F}_{\text {rro }}=$ Ko@Swi / Ko1@Swi

The detailed discretions of the experimental results from Wanaea core flooding tests are discussed individually for each chemical. The discussion mainly is based on permeability modification before and after the treatments in term of $\mathrm{F}_{\text {rrw }}$ and $\mathrm{F}_{\text {rro }}$ (Fig 3). 


\section{- WaterWeb}

Of all the chemicals used, Waterweb caused the most significant reduction in water permeability, $\mathrm{F}_{\text {rrwl }}$ of 2.61, which was sustained and reduced even further through the subsequent flushing cycle, yielding $\mathrm{F}_{\text {rrw2 }}$ of 3.05. However, the chemical has limited application in that the permeability to oil was reduced even more than the permeability to water, $F_{\text {rro }}$ of 3.15 .

\section{- AquaCon}

AquaCon demonstrates similar behavior to WaterWeb, except that permeability reduction is not as significant $\left(\mathrm{F}_{\text {rrw1 }}\right.$ of 1.12, $\mathrm{F}_{\text {rrw2 }}$ of 2.00, and $\mathrm{F}_{\text {rro }}$ of 1.96).

\section{- Reltreat}

Like Aquacon, Reltreat demonstated a minor reduction in water permeability when the chemical was first injected ( $\mathrm{F}_{\text {rrwl }}$ of 1.11). As for both Waterweb and Aquacon, Reltreat reduced water permeability even further with subsequent oil and water flushing ( $F_{\text {rrw2 }}$ of 1.67). However, the permeability to oil was not as impaired as it was for Waterweb and Aquacon ( $F_{\text {rro }}$ of 0.992). These results would seem to make Reltreat a good candidate chemical, except that water permeability reduction is probably not sufficiently significant to warrant the expense of field injection.

\section{- RAC}

The RAC chemical appeared to have an effect more like a surfactant than a traditional RPM in that a reduction in residual oil saturation was observed upon chemical injection, causing an increase in water permeability ( $\mathrm{F}_{\text {rrwl }}$ of 0.293$)$. However, when oil, then water was subsequently flowed through the sample, an $\mathrm{F}_{\text {rrw2 }}$ of 1.07 was recorded. In other words, RAC had a negligible overall $\mathrm{Kw}$-reduction effect. This $\mathrm{F}_{\text {rrw } 2}$ result probably occurred because the original Sor before chemical treatment was re-established after the second oil flush. It was noted that, as for Reltreat, oil permeability actually increased as a result of RAC chemical injection ( $\mathrm{F}_{\text {rro }}$ of 0.714$)$.

\subsection{Discussion:}

The initial threshold for successful treatment is that the $\mathrm{F}_{\text {rrw }}$ to water should be higher than the $\mathrm{F}_{\text {rro }}$ to oil. In other words, the ratio to which the oil permeability decreases with chemical treatment should not be as great as the ratio to which water permeability decreases. When $F_{\text {rrw2 }}$ has the same or greater value than $F_{\text {rrwl }}$ then permeability reduction to water after chemical injection has been sustained. In addition, according to Seright (2006) for bull head treatment in the case of no zone isolation, compromising excessive water production by gels in matrix reservoirs that are associated with radial flow will be successful if the gels display residual resistance factor to water greater than 20 and at the same time should display less than 2 for oil (Liang et al, 1993; Seright, 1988). On the other hand, Zaitoun et al (1989) states that water permeability should not be reduced by a factor greater than 10 . Hence the amount to drop water permeability after the treatment is still controversial, so this research work has preferred to select candidate chemicals that display $\mathrm{F}_{\text {rrw }}$ that lie in a range betweens 8-15 for curing excessive water production in Wanaea matricial reservoirs. A point to be noted, all chemicals have shown higher residual resistance factor when the second water cycle was performed (Kw2) through the core plugs (See table 3). 
This phenomenon can be interpreted as some of the oil re-established in the pore spaces after running Ko1 cycle. This therefore, has resulted in the lower water permeability during implementing Kw2 cycle. The result of residual resistance factor to water and oil is shown in the Figure $3, \mathrm{~F}_{\text {rrw }}$ of the two water cycles Kw1 and Kw2 after the treatment are calculated by dividing the endpoint water mobility of (Kw1 \& Kw2) by their initial water permeability at (Kw @ Sor).

\section{Conclusion}

All chemicals tested demonstrated the ability to modify water permeability. However, only Reltreat chemical meets the criterion as it displays low $\mathrm{F}_{\text {rro }}$ (Kol) value and high $\mathrm{F}_{\text {rrw }}$ (Kw1) value. But its residual resistance factor for water is less than the range of this research work limit. Therefore, none of the results were sufficiently favourable to warrant the expense of a field trial.

\section{Recommendations}

Further work proposed includes: fine tuning chemical formulations; sequential chemical injection to investigate reduction of cross-bed flow of water in the reservoir around the chemically treated area.

\section{Acknowledgment}

The Authors wish to thank Woodside Energy for supporting this project, and in particular Mr. Stephen Hamilton and Core Laboratories Australia.

\section{Nomenclature}

$\mathbf{F}_{\mathrm{rr}}=$ Residual resistance factor

$K w_{\text {before }}=$ Water permeability before chemical treatments (Kw@ Sor), md.

$K w_{\text {affer }}=$ Water permeability after chemical treatments $(\mathrm{Kw} 1 \& 2), \mathrm{md}$. 


\section{References:}

Amanullah, M., 2006. Experimental evaluation of the blockage efficiency of a novel gel system to mitigate water-cut problem of producing wells. SPE 99491, 2-5.

Bailey, B., Crabtree, M., Tyrie, J., Elphich, J., Kuchuk, F., Romano, C., Roodhart, L., 2000. Water control Oilfield Review. Retrieved November 5, 2006, from w.oilfield.slb.com/media/services/resources/oilfieldreview/ors00/spr00/p30_51.pdf

Halliburton, 1996 .Conformance Technology. Halliburton Energy Services Publication, USA.

Kume, N., 2003. An engineering approach to predicting post-treatment performance using selective chemical water shut-off techniques: An RPM example. SPE 84513.

Liang, J., Lee, R., Seright, R.S., 1993 .Gel Placement in Production Wells. SPEPF, 276-284.

Mennella, A., Chiappa, L., Burrafato, G., 1998 .Candidate and chemical selection rules for water shutoff polymer treatments. SPE 54736, 2-3.

Ranjbar, M., Schaffie, M., 1999 .Improved treatment of acrylamide co- and terpolymers for water control in gas -producing and storage wells. Journal of Petroleum Science and Engineering, vol 26, 133-141.

Seright, R.S., 1988 .Placement of gels to modify injection profiles. SPE/DOE 17332.

Seright, R.S., Marin, F., 1993 .Impact of gelation pH, rock permeability, and lithology on the performance of a monomer-based gel. SPE Reservoir Engineering, 43-49

Seright, R.S., 2006. Optimizing disproportionate permeability reduction. SPE 99443.

Zaitoun, A., Kohler, N., Codreanu, D., Denys K., 1989 .Water shutoff by relative permeability modifiers: lessons from several field applications. SPE 56740, p 3. 


\title{
A laboratory investigation of water abatement chemicals for potential use in the Wanaea field
}

\author{
Hiwa Sidiq ${ }^{\mathrm{a},{ }^{*}}$, Robert Amin ${ }^{\mathrm{b}}$, Tony Kennaird ${ }^{\mathrm{c}}$ \\ ${ }^{\mathrm{a}, \mathrm{b}}$ Woodside Research Facility, Curtin University of Technology, Perth, Australia \\ ${ }^{c}$ Core Laboratories, Perth, Australia \\ * corresponding author: \\ Tel: (+61) 89266 1346; Fax: (+61) 892664848 \\ Address: SPO Box U1987, Perth WA 6845 \\ Email: h.sidiq@postgrad.curtin.edu.au (H. sidiq) \\ R.Amin@curtin.edu.au (R. Amin) \\ Tony.Kennaird@corelab.com (T. Kennaird)
}

\begin{abstract}
The disadvantages of water influx into a producing well include reduced relative permeability to hydrocarbon and increased expenses for both water handling and corrosion control. An effective water control technique is, therefore, highly desirable. One potential solution for reducing excessive water production is the injection of "Relative Permeability Modifier" (RPM) chemicals into producing wells. The work described in this paper is concerned with finding a highly selective chemical to reduce water production without affecting oil production. Presented herein are results of laboratory tests using relative permeability modifiers in conjunction with core samples from the Wanaea field.
\end{abstract}

The oil producing Wanaea field is operated by Woodside Energy. This field is in offshore Western Australian waters. Some of the wells suffer from high water cut, therefore the introduction of a relative permeability modifier (RPM) has been considered.

Four RPM chemicals were tested with core plugs taken from Unit II of well Wanaea-3 (core depth 2832.00 to $2844.50 \mathrm{~m}$ ). Laboratory experiments were conducted on 4 reservoir core plugs, with air permeabilities ranging from 158 to $334 \mathrm{md}$ and porosities from 16.4 to $19.9 \%$. The objective of the tests was to assess the effectiveness of selected RPM's in selectively reducing water production.

The experimental results demonstrated that the chemicals were variably effective in reducing the relative permeability to the water phase, but they also variably affected the relative permeability to the oil phase. 


\section{Introduction}

Excessive water production is an inevitable consequence of declining oil production when waterflooding is used to develop an oil reservoir or when the field drive mechanism involves strong aquifer support. It is a problem of paramount importance from technical, environmental and oil production points of view (Amanullah, 2006). The remedy of excessive water production costs worldwide \$US 40 billion annually, whereas in the U.S the disposing cost of this water is estimated to be \$US 5-10 billion (Bailey et al., 2000). These costs include the expense to lift, dispose or re-inject, and the capital cost of surface facility construction to ensure that environmental regulations are met (Halliburton, 1996). Hence, water control should not be seen only in terms of increasing incremental oil production, but also in terms of reduction of operating costs associated with water production, both material and environmental (Kume, 2003). Therefore a technology that can block water in situ is highly desirable.

Downhole treatment based on polymers called relative permeability modifiers (RPM), works on the basis of the chemicals attaching themselves to the rock surface to reduce water mobility. This technique for conformance control has been often represented as a valid and economic alternative solution. However each RPM technology needs detailed pre-application testing to ensure the treatment will be appropriate in terms of it is applicability to the particular reservoir mineralogy, permeability, brine salinity, temperature and pressure (Zaitoun et al., 1989; Seright, 1993; Mennella, 1998).

The objective of this study is to evaluate chemicals that might effectively reduce water production in the Wanaea reservoir, situated offshore on the Australian North West Shelf. As some of the wells are producing high water cut, chemical abatement has been proposed, with the aim of reducing water production selectively without any significant reduction in hydrocarbon production. Core tests have been undertaken to examine the effectiveness of four different chemicals at reservoir conditions.

Three commercially available chemicals (WaterWeb, Reltreat and AquaCon) plus a research chemical (RAC) formulated at Curtin University by Professor Amin were tested. Reservoir parameters such as formation brine salinity, temperature, reservoir rock mineralogy and oil properties were taken into consideration for detailed formulation of the chemicals.

\section{Test Methods}

Linear core flooding experiments were performed on the Wanaea core samples with the aim of evaluating various RPM chemicals at reservoir conditions of temperature $\left(110^{\circ} \mathrm{C}\right)$ and effective overburden pressure (2250 psi). The simulated brine used in the tests was prepared by dissolving 24 grams of $\mathrm{NaCl}$ in each litre of solution using distilled water. The resulting $24000 \mathrm{mg} / \mathrm{l}$ salinity approximated the salinity of the Wanaea formation brine. The oil used in this study was filtered stock tank Wanaea crude. 


\section{Core Plug Preparation and Testing}

The core plugs used in the tests were from the Wanaea reservoir. Basic core analysis measurements carried out by Core Laboratories Australia indicated that the air permeability ranged from 158 to $334 \mathrm{mD}$ and the porosity varied from 16.4 to $19.9 \mathrm{vol} \%$. The core plugs were approximately $7.3 \mathrm{~cm}$ in length and $3.80 \mathrm{~cm}$ in diameter. The properties and depths of the tested cores are listed in Table 1. The selected core plugs had been cleaned with toluene and methanol using soxhlet extraction before basic measurements of porosity and air permeability were performed.

The cores were evacuated and pressure saturated with the simulated formation brine and loaded individually into core holders for testing on a sequential basis. Each loaded sample was then placed in an air-bath and the temperature increased to the Wanaea reservoir representative temperature of $110{ }^{\circ} \mathrm{C}$. A confining pressure of $3250 \mathrm{psi}$ and a pore pressure of $1000 \mathrm{psi}$ were maintained throughout the analytical sequences. The core flood tests followed the sequence of steps as shown in Table 2, with some variation with respect to chemical injection as some of the chemicals required a pre-flush before the main chemical treatment.

Each of four samples was tested with a different RPM (Waterweb, Aquacon, Reltreat, RAC) while a fifth sample was used as a control. This control sample was subjected to the same sequence of testing (comprising multiple cycles of oil and water flow) as the other four samples except that there was no chemical treatment. Results from the control sample were used to determine whether or not variations in oil and/or water permeability were simply a result of hysteresis effects created by changes in fluids saturation distribution in the pore spaces during the multiple flow cycles.

The oil permeability at immobile water saturation (Ko@ Swi) and the water permeability at residual oil saturation ( $\mathrm{Kw} @$ Sor) were measured before chemical injection. After chemical injection all samples (except the control) were injected with one of the four chemicals under test and the following measurements were made:

--Kw1@ Sor: This permeability was compared directly to the value of Kw @ Sor before chemical injection to determine if any reduction in water permeability had taken place

--Ko1@ Swi: This permeability was compared to the value of Ko @ Sor measured before chemical injection to determine if chemical treatment had caused an unwanted reduction in oil permeability.

--Kw2@ Sor: This permeability was compared to both Kw @ Sor and Kw1@ Sor to determine if any water permeability reduction resulting from chemical injection (as demonstrated by Kw1 @ Sor vs Kw@Sor) could be sustained after subsequent oil and water flush cycles (since substantial oil and water flushing of a chemically injected zone would occur around a treated production well in the reservoir). 


\section{Results and discussion:}

\subsection{Results:}

A point to be noted in the course of $100 \mathrm{PV}$ of brine flooding; water permeability at Kw1 and Kw2 were nearly stable after flooding the sample with approximately 15 pore volumes (PV) of water, except Reltreat chemical at Kw1 test ( See Fig $1 \&$ 2). Both RAC and Reltreat chemicals gain strength with time as water permeability (Kw1) decreases through the cycle of $100 \mathrm{PV}$ flooding. In contrast, WaterWeb and AquaCon chemicals show degradation with brine flooding (Kw1) up to $15 \mathrm{PV}$. This observation reflects the fact some of the chemical have broke down when the core is flushed with brine.

In general after subsequent flushing the sample with crude oil, water permeability has reduced remarkably at Kw2 if comparing Kw1 with $\mathrm{Kw} 2$ (See Fig 1 \& 2). The RAC sample is significantly affected by alternating oil and brine injection $(\mathrm{Kw} 1=25.9 \mathrm{md}, \mathrm{Kw} 2=7.1 \mathrm{md})$. However Kw1 \& Kw2@WeterWeb shows some variation but most of the flooding course stayed approximately at the same level (See Table 3). During the RAC chemical's injection a considerable amount of residual crude oil was mobilized, consequently water permeability (Kw1) is obviously increased because of the lower Sor. It is difficult to know the exact volume of oil mobilized as the chemical appears to be miscible with the oil.

\subsection{Residual Resistance Factor}

To facilitate comparison of results both for individual sample cycles and for the four different chemical treatments, the data is also expressed in terms of Residual Resistance Factors $\left(\mathrm{F}_{\mathrm{rr}}\right)$. High values of residual resistance factors $\left(\mathrm{F}_{\text {rrw }}\right)$ for brine flow and low $\left(\mathrm{F}_{\text {rro }}\right)$ values for gas/oil flow means that the chemicals have the ability to control water production with minor effects on gas production. The $\mathrm{F}_{\mathrm{rr}}$ to brine and gas were determined using equation:

$$
\mathrm{F}_{r r w}=K w_{\text {before }} / K w_{\text {affer }}
$$

Where

$K w_{\text {before }}=$ Water permeability before chemical treatments $(\mathrm{Kw} @$ Sor $)$.

$K w_{\text {affer }}=$ Water permeability after chemical treatments $(\mathrm{Kw} 1 \& 2)$.

For this research work residual resistance factor $\left(\mathrm{F}_{\mathrm{rr}}\right)$ to both brine and oil are calculated as follows for the subsequent cycles:

$\mathrm{F}_{\mathrm{rrw1}}=\mathrm{Kw} @$ Sor / Kw1@Sor

$\mathrm{F}_{\mathrm{rrw} 2}=\mathrm{Kw} @$ Sor $/ \mathrm{Kw} 2 @$ Sor

$\mathrm{F}_{\text {rro }}=$ Ko@Swi / Ko1@Swi

The detailed discretions of the experimental results from Wanaea core flooding tests are discussed individually for each chemical. The discussion mainly is based on permeability modification before and after the treatments in term of $\mathrm{F}_{\text {rrw }}$ and $\mathrm{F}_{\text {rro }}$ (Fig 3). 


\section{- WaterWeb}

Of all the chemicals used, Waterweb caused the most significant reduction in water permeability, $\mathrm{F}_{\text {rrwl }}$ of 2.61, which was sustained and reduced even further through the subsequent flushing cycle, yielding $\mathrm{F}_{\text {rrw2 }}$ of 3.05. However, the chemical has limited application in that the permeability to oil was reduced even more than the permeability to water, $F_{\text {rro }}$ of 3.15 .

\section{- AquaCon}

AquaCon demonstrates similar behavior to WaterWeb, except that permeability reduction is not as significant $\left(\mathrm{F}_{\text {rrw1 }}\right.$ of 1.12, $\mathrm{F}_{\text {rrw2 }}$ of 2.00, and $\mathrm{F}_{\text {rro }}$ of 1.96).

\section{- Reltreat}

Like Aquacon, Reltreat demonstated a minor reduction in water permeability when the chemical was first injected ( $\mathrm{F}_{\text {rrwl }}$ of 1.11). As for both Waterweb and Aquacon, Reltreat reduced water permeability even further with subsequent oil and water flushing ( $F_{\text {rrw2 }}$ of 1.67). However, the permeability to oil was not as impaired as it was for Waterweb and Aquacon ( $F_{\text {rro }}$ of 0.992). These results would seem to make Reltreat a good candidate chemical, except that water permeability reduction is probably not sufficiently significant to warrant the expense of field injection.

\section{- RAC}

The RAC chemical appeared to have an effect more like a surfactant than a traditional RPM in that a reduction in residual oil saturation was observed upon chemical injection, causing an increase in water permeability ( $\mathrm{F}_{\text {rrwl }}$ of 0.293$)$. However, when oil, then water was subsequently flowed through the sample, an $\mathrm{F}_{\text {rrw2 }}$ of 1.07 was recorded. In other words, RAC had a negligible overall $\mathrm{Kw}$-reduction effect. This $\mathrm{F}_{\text {rrw } 2}$ result probably occurred because the original Sor before chemical treatment was re-established after the second oil flush. It was noted that, as for Reltreat, oil permeability actually increased as a result of RAC chemical injection ( $\mathrm{F}_{\text {rro }}$ of 0.714$)$.

\subsection{Discussion:}

The initial threshold for successful treatment is that the $\mathrm{F}_{\text {rrw }}$ to water should be higher than the $\mathrm{F}_{\text {rro }}$ to oil. In other words, the ratio to which the oil permeability decreases with chemical treatment should not be as great as the ratio to which water permeability decreases. When $F_{\text {rrw } 2}$ has the same or greater value than $F_{\text {rrwl }}$ then permeability reduction to water after chemical injection has been sustained. In addition, according to Seright (2006) for bull head treatment in the case of no zone isolation, compromising excessive water production by gels in matrix reservoirs that are associated with radial flow will be successful if the gels display residual resistance factor to water greater than 20 and at the same time should display less than 2 for oil (Liang et al, 1993; Seright, 1988). On the other hand, Zaitoun et al (1989) states that water permeability should not be reduced by a factor greater than 10 . Hence the amount to drop water permeability after the treatment is still controversial, so this research work has preferred to select candidate chemicals that display $\mathrm{F}_{\text {rrw }}$ that lie in a range betweens 8-15 for curing excessive water production in Wanaea matricial reservoirs. A point to be noted, all chemicals have shown higher residual resistance factor when the second water cycle was performed (Kw2) through the core plugs (See table 3). 
This phenomenon can be interpreted as some of the oil re-established in the pore spaces after running Ko1 cycle. This therefore, has resulted in the lower water permeability during implementing Kw2 cycle. The result of residual resistance factor to water and oil is shown in the Figure 3, Frrw of the two water cycles Kw1 and Kw2 after the treatment are calculated by dividing the endpoint water mobility of $(\mathrm{Kw} 1 \& \mathrm{Kw} 2)$ by their initial water permeability at (Kw (a) Sor).

\section{Conclusion}

All chemicals tested demonstrated the ability to modify water permeability. However, only Reltreat chemical meets the criterion as it displays low $\mathrm{F}_{\text {rro }}$ (Kol) value and high $\mathrm{F}_{\text {rrw }}(\mathrm{Kw} 1)$ value. But its residual resistance factor for water is less than the range of this research work limit. Therefore, none of the results were sufficiently favourable to warrant the expense of a field trial.

\section{Recommendations}

Further work proposed includes: fine tuning chemical formulations; sequential chemical injection to investigate reduction of cross-bed flow of water in the reservoir around the chemically treated area.

\section{Acknowledgment}

The Authors wish to thank Woodside Energy for supporting this project, and in particular Mr. Stephen Hamilton and Core Laboratories Australia.

\section{Nomenclature}

$\mathbf{F}_{\mathrm{rr}}=$ Residual resistance factor

$K w_{\text {before }}=$ Water permeability before chemical treatments (Kw@ Sor).

$K w_{\text {affer }}=$ Water permeability after chemical treatments $(\mathrm{Kw} 1 \& 2)$. 


\section{References:}

Amanullah, M., 2006. Experimental evaluation of the blockage efficiency of a novel gel system to mitigate water-cut problem of producing wells. SPE 99491, 2-5.

Bailey, B., Crabtree, M., Tyrie, J., Elphich, J., Kuchuk, F., Romano, C., Roodhart, L., 2000. Water control Oilfield Review. Retrieved November 5, 2006, from w.oilfield.slb.com/media/services/resources/oilfieldreview/ors00/spr00/p30_51.pdf

Halliburton, 1996 .Conformance Technology. Halliburton Energy Services Publication, USA.

Kume, N., 2003. An engineering approach to predicting post-treatment performance using selective chemical water shut-off techniques: An RPM example. SPE 84513.

Liang, J., Lee, R., Seright, R.S., 1993 .Gel Placement in Production Wells. SPEPF, 276-284.

Mennella, A., Chiappa, L., Burrafato, G., 1998 .Candidate and chemical selection rules for water shutoff polymer treatments. SPE 54736, 2-3.

Ranjbar, M., Schaffie, M., 1999 .Improved treatment of acrylamide co- and terpolymers for water control in gas -producing and storage wells. Journal of Petroleum Science and Engineering, vol 26, 133-141.

Seright, R.S., 1988 .Placement of gels to modify injection profiles. SPE/DOE 17332.

Seright, R.S., Marin, F., 1993 .Impact of gelation pH, rock permeability, and lithology on the performance of a monomer-based gel. SPE Reservoir Engineering, 43-49

Seright, R.S., 2006. Optimizing disproportionate permeability reduction. SPE 99443.

Zaitoun, A., Kohler, N., Codreanu, D., Denys K., 1989 .Water shutoff by relative permeability modifiers: lessons from several field applications. SPE 56740, p 3. 
Table 1: Basic properties of the core samples tested.

\begin{tabular}{||c|c|c|c|c|c|c|c|c||}
\hline $\begin{array}{c}\text { SAMPLE } \\
\text { NO. }\end{array}$ & $\begin{array}{c}\text { Depth } \\
\mathbf{( M )}\end{array}$ & $\begin{array}{c}\text { TREATMENT } \\
\text { CHEMICAL }\end{array}$ & $\begin{array}{c}\text { Length } \\
\mathbf{( C m )}\end{array}$ & $\begin{array}{c}\text { Area } \\
\left(\mathbf{C m}^{\mathbf{2}}\right)\end{array}$ & $\begin{array}{c}\text { PV } \\
\left(\mathbf{C m}^{\mathbf{3}}\right)\end{array}$ & $\begin{array}{c}\mathbf{G D} \\
\left(\mathbf{g} / \mathbf{c m}^{3}\right)\end{array}$ & $\begin{array}{c}\text { POROSITY } \\
\mathbf{( \% )}\end{array}$ & $\begin{array}{c}\text { Ka } \\
(\mathbf{m d})\end{array}$ \\
\hline \hline $\mathbf{2 7}$ & 2839.1 & Waterweb & 7.42 & 11.4 & 16.79 & 2.65 & 19.9 & 334 \\
\hline $\mathbf{1 3}$ & 2834.9 & AquaCon & 7.43 & 11.4 & 15.86 & 2.67 & 18.5 & 291 \\
\hline $\mathbf{3 7}$ & 2842.1 & Reltreat & 7.42 & 11.4 & 14.15 & 2.69 & 16.4 & 181 \\
\hline $\mathbf{2 3}$ & 2837.9 & RAC & 6.59 & 11.34 & 13.35 & 2.66 & 17.5 & 158 \\
\hline $\mathbf{1 1}$ & 2834.3 & Control Sample & 7.41 & 11.4 & 14.81 & 2.68 & 18.5 & 260 \\
\hline
\end{tabular}

Table 2: Sequence of the tests.

\section{PROCESS}

- $\quad$ Measure permeability to air on clean, dry core samples and Berea sandstone sample. Ka

- Stabilize temperature of air bath and equipment at $70 \mathrm{deg} C$ for 24 hours.

- Saturate samples with $24,000 \mathrm{mg} / \ell$ brine.

○ Measure water permeability at $100 \%$ brine saturation. Kw

- Flush samples with crude oil to immobile water saturation, aging overnight.

○ Measure oil permeability at immobile water saturation. Ko@Swi

- Flood samples with $24,000 \mathrm{mg} / \ell$ brine to residual oil saturation.

○ Measure water permeability at residual oil saturation. Kw@Sor

- $\quad$ Flow chemical solutions:

○ 2 Pore Volumes (PV).

- $\quad$ Shut-in chemicals overnight.

○ Re-measure water permeability at residual oil saturation. Kw1@Sor

- Flush samples with the mineral oil (100 PV) to immobile water saturation.

○ Measure oil permeability at residual water saturation. Ko1@Swr

- Flush samples with brine (100 PV) to residual oil saturation.

○ Measure water permeability at residual oil saturation. Kw2@Sor

Table 3: Summary of the test results before and after chemical treatments.

\begin{tabular}{||c|c|c|c|c|c|c||}
\hline \multirow{2}{*}{ ITEM } & \multirow{2}{*}{ MEASUREMENT } & \multicolumn{5}{|c||}{ PERMEABILITY, md } \\
\cline { 3 - 8 } & & WATERWEB & AQUACON & RELTREAT & RAC & CONTROL \\
\hline \hline 1 & Ka & 334 & 291 & 181 & 158 & 260 \\
\hline 2 & Kw & 190 & 146 & 127 & 77.9 & 195 \\
\hline 3 & Ko @ Swi & 95 & 82 & 92.4 & 53.3 & 85.6 \\
\hline 4 & Kw @ Sor & 12.8 & 27.6 & 15.7 & 7.6 & 12.9 \\
\hline 5 & Kw1 @ Sor & 4.9 & 24.6 & 14.1 & 25.9 & 12.2 \\
\hline 6 & Ko1 @ Swr & 30.2 & 41.9 & 93.1 & 74.6 & 89.3 \\
\hline 7 & Kw2 @ Sor & 4.2 & 13.8 & 9.4 & 7.1 & 12.0 \\
\hline
\end{tabular}




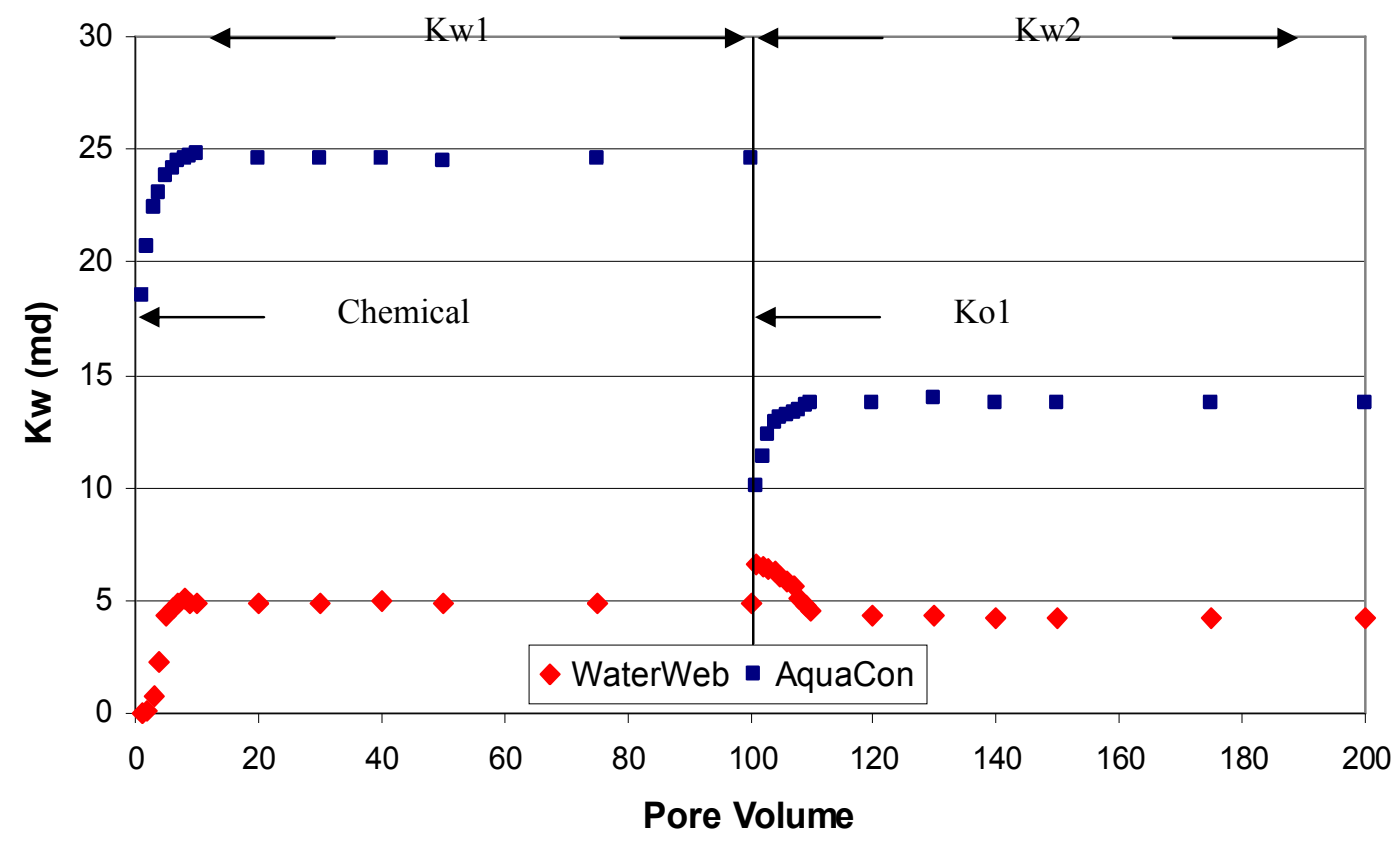

Fig. 1: Water permeability status after chemicals and subsequent oil, brine flushing.

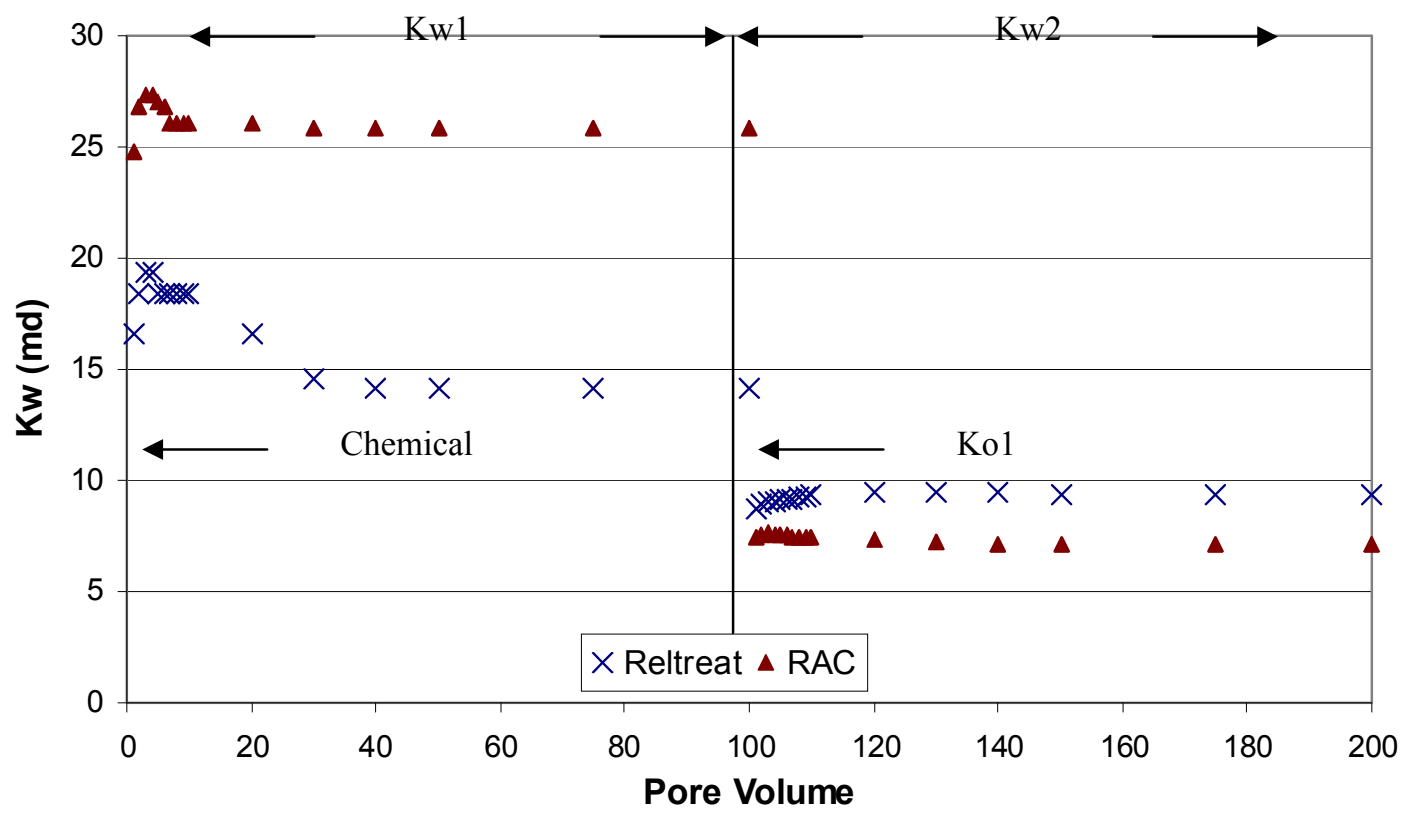

Fig. 2: Water permeability status after chemicals and subsequent oil, brine flushing. 


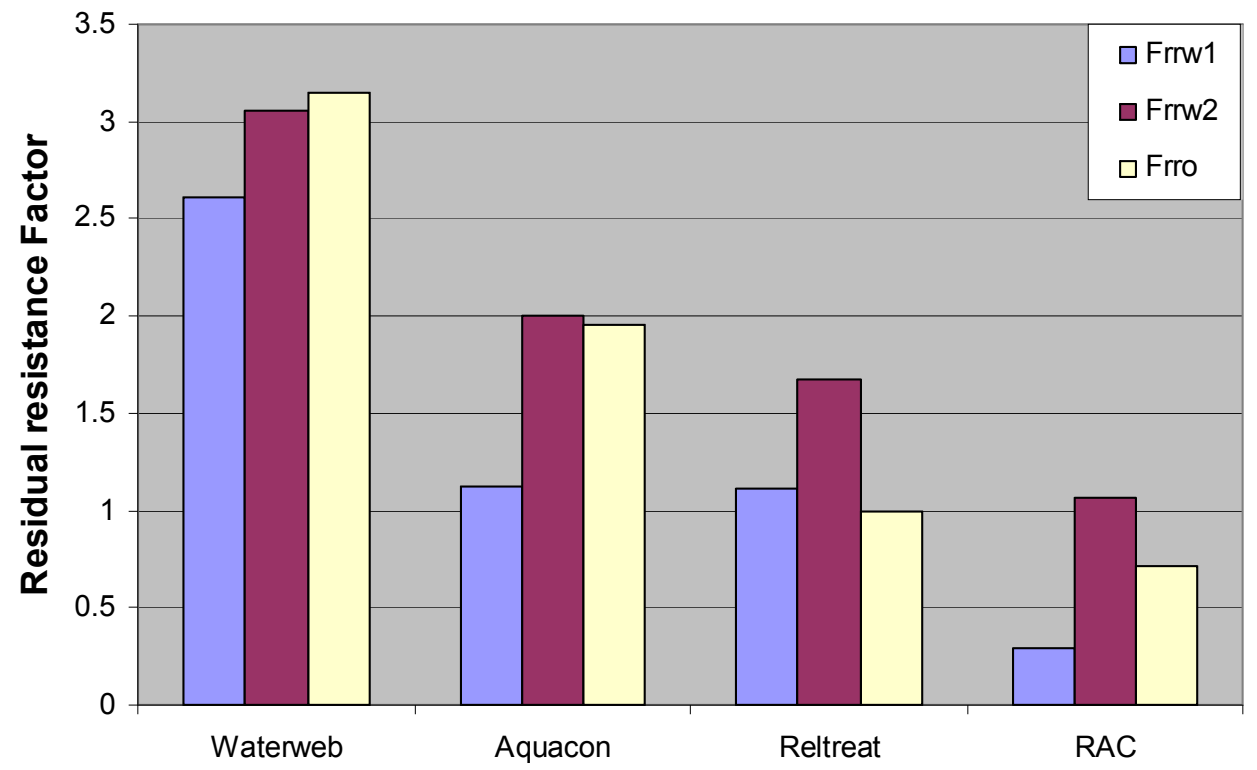

Figure 3: Residual resistance factor of brine and oil. 